\title{
The Relationship Between Tort Reform and Medical Utilization
}

\author{
Kevin T. Kavanagh, MD, MS, * Lindsay E. Calderon, PhD, † and Daniel M. Saman, DrPH, MPH, CPH*
}

\begin{abstract}
Introduction: The hidden cost of defensive medicine has been cited by policymakers as a significant driving force in the increase of our nation's health-care costs. If this hypothesis is correct, one would expect that states with higher levels of tort reform will have a decrease in Medicare utilization and that medical utilization will decrease after tort reform is enacted. Methods: State-level reimbursement data for years 1999 to 2010 (the last year available) was obtained from the Dartmouth Atlas of Health Care. Medical tort rankings for the 50 states were obtained from the Pacific Research Institute (PRI) and correlated with state medical utilization for the year 2010. In 3 states, Mississippi, Nevada, and Texas, data were available to make pretort and posttort reform comparisons.

Results: Data analysis between total state Medicare Reimbursements and the PRI's tort rankings showed no significant observed correlation. In 6 Medicare utilization categories (total Medicare, hospital and skilled nursing facility, physician, home health agency, hospice, and durable medical equipment), a negative trend was observed when correlated with PRI tort rankings. This trend does not support the hypothesis that defensive medicine is a major driver of health-care expenditures. Tracking expenditures in the states of Texas, Nevada, and Mississippi, before and after passage of comprehensive medical tort reform gave inconsistent results and did not demonstrate substantial or meaningful total Medicare savings. In Mississippi, there was a trend of decreased expenditures after medical tort reform was passed. However, in Texas, where $80 \%$ of the analyzed enrollees resided, there was a trend of progressive increasing expenditures after tort reform was passed.
\end{abstract}

Conclusion: The comparison of the Dartmouth Atlas Medicare Reimbursement Data with Malpractice Reform State Rankings, which are used by the PRI, did not support the hypothesis that defensive medicine is a driver of rising health-care costs. Additionally, comparing Medicare reimbursements, premedical and postmedical tort reform, we found no consistent effect on health-care expenditures. Together, these data indicate that medical tort reform seems to have little to no effect on overall Medicare cost savings.

Key Words: Medicare, utilization, reimbursements, health-care costs, tort reform, malpractice reform, Pacific Research Institute, Dartmouth institute, atlas, U.S. health-care expenditures

(J Patient Saf 2013;00: 00-00)

$\mathrm{T}^{\mathrm{h}}$ he rising cost of health care is a major concern to patients and policymakers because of its influence on health-care access and the U.S. economy. The United States spends 17.6\% of

From *Health Watch USA, Somerset, Kentucky; †Eastern Kentucky University, Richmond, Kentucky; and $\ddagger$ Essentia Institute of Rural Health, Duluth, Minnesota.

Correspondence: Kevin T. Kavanagh, MD, MS, 3396 Woodhaven Drive, Somerset, KY 42503 (e-mail: kavanagh.ent@gmail.com).

The authors declare no conflicts of interest. No outside funding was received for writing or publication of this manuscript.

This is an open-access article distributed under the terms of the Creative Commons Attribution-NonCommercial-NoDerivitives 3.0 License, where it is permissible to download and share the work provided it is properly cited. The work cannot be changed in any way or used commercially. http://creativecommons.org/licenses/by-nc-nd/3.0.

Copyright (C) 2013 by Lippincott Williams \& Wilkins its gross domestic product (GDP) on health care, which is $47 \%$ higher than the next highest industrial nation, the Netherlands. ${ }^{1}$ The 2013 Medicare Payment Advisory Committee (MedPAC) report to Congress stated that U.S. health-care spending is growing faster than GDP, and in 2024, it is projected to exhaust the Medicare Hospital Insurance Trust Fund. ${ }^{2}$ In 2012, Medicare accounted for $21 \%$ of the total U.S. health-care expenditures, $24 \%$ of the Medicare dollar was spent on physician services and $28 \%$ on hospital care. ${ }^{3}$ Medicare spending is also projected to grow $6 \%$ per year, with half of this growth due to increased cost per beneficiary and half due to increasing number of beneficiaries. ${ }^{2}$

Reducing health-care overuse is of paramount importance because such reductions not only save money but will increase health-care quality and safety by avoiding exposing patients to unnecessary risks. ${ }^{4}$ A Dartmouth Institute report (2010) estimated if spending per beneficiary in all Medicare Referral Regions were brought into line with low-spending regions, approximately $30 \%$ of Medicare dollars would be saved. ${ }^{5}$

Overutilization of health care has come to the forefront as one of the drivers of increasing health-care expenditures. All medical specialties have been affected; two fields that have been researched extensively in their over utilization are imaging studies and cardiac procedures.

Imaging studies are relatively fast and often easy to do, and the public has the general impression that all are safe. In truth, a number of studies have found that there is a significant increase in lifetime risk of cancer from medical radiation exposure. Berrington de González et $\mathrm{al}^{6}$ estimated that there will be 29,000 future cancers related to CT scans performed in 2007 . Sodickson et $\mathrm{al}^{7}$ estimated that $15 \%$ of the population has received a radiation dosage of more than $100 \mathrm{mSv}$ and that CT exposure was responsible for $1 \%$ of all cancer deaths. Despite this, there has been a steady increase in utilization of diagnostic imaging, evidenced by a $7.8 \%$ annual increase in CT scan utilization from 1996 to 2010 , resulting in almost a 3 -fold increase over this time span. ${ }^{8}$ In addition, there is wide variation between providers, as imaging utilization has been shown to vary 2 to 3 fold between different physicians in the same emergency room. ${ }^{9}$

With regard to cardiac procedures, there are also significant risks of performing unnecessary cardiovascular surgery and stenting. Despite these risks, only $50 \%$ of angioplasties performed on nonacute patients were judged to be appropriate, $38 \%$ were judged to be uncertain and $12 \%$ as inappropriate. ${ }^{10}$ Similarly, it has been shown that more than 1 in 5 patients have received a defibrillator without meeting insertion criteria. ${ }^{11}$

Defensive medicine has been cited by policymakers as a significant driving force in overutilization and the increase of our nation's health-care costs. ${ }^{12}$ It has been estimated that defensive medicine costs the U.S. health-care system up to $\$ 124$ billion dollars annually. ${ }^{13}$ The Massachusetts Medical Society surveyed 3650 physicians in Massachusetts regarding defensive medicine and found that $82 \%$ of respondents stated they practiced defensive medicine, which accounted for overutilizing plain x-rays by $22 \%$, CT scans by $28 \%$, specialty referrals by $28 \%$, and hospital admissions by $13 \% .{ }^{14}$ Hendee et al attributed $5 \%$ to $25 \%$ of the total cost of medical imaging procedures to defensive medicine. ${ }^{15}$ 
The effect of tort reform on Medicare cost savings remains undetermined. To test whether tort reform was associated with medical utilization and, hence, costs, we compared states' tort reform rankings used by conservative policy think tanks with Medicare state level reimbursement data from the Dartmouth Atlas. We hypothesized states with higher levels of tort reform will have a decrease in Medicare utilization. In addition, we compared Medicare reimbursements prereform and postreform in 3 states ranked by the Pacific Research Institute (PRI) as having comprehensive medical tort reform.

\section{METHODS}

\section{Medicare Reimbursements Compared With the Comprehensiveness of Medical Tort Reform}

State-level traditional Medicare provider reimbursement data per enrollee for the year 2010 (the most recent year available) was obtained from the Dartmouth Atlas of Health Care. ${ }^{16}$ These data were a $100 \%$ sampling of traditional Medicare enrollees and was price, age, sex, and race adjusted. The sampling did not include Medicare Advantage plan enrollees. Medical tort rankings for the 50 states were obtained from the PRI (2010). ${ }^{17}$ The report can be downloaded from the PRI's or Heartland Institute's Website. ${ }^{18}$ This ranking system evaluates 8 relevant variables in medical tort reform including the following: caps on punitive damages, attorneyfee limits, caps on noneconomic damages, pretrial screening, and conditions of use of expert witnesses. States with significant tort reform have lower rankings on PRI's medical tort reform index. A positive correlation with Medicare reimbursements would be expected if tort reform results in decreased health-care utilization.

Total state Medicare spending per enrollee along with 6 other categories (shown in Table 1) was evaluated. Correlations between these data and the PRI's medical tort rankings were done by calculation of $R$ and $R^{2}$ values.

\section{Prereform and Postreform Reimbursements}

To estimate the effect of tort reform on traditional Medicare reimbursements per enrollee, the states with the most comprehensive tort reform as ranked by PRI were analyzed. Two data sets were analyzed from the Dartmouth Institute (for years 1996-2007 and 2003-2010). The 2 data sets were not in the same format. The sampling did not include Medicare Advantage plan enrollees.

The top 6 PRI-ranked tort reform states were Mississippi, Nevada, Michigan, Colorado, Louisiana and Texas. Michigan, Colorado, and Louisiana were not analyzed because major tort reform took place in 1993, 1988, and 1974, respectively. It is

TABLE 1. Correlation of State Malpractice Reform and Medicare Utilization

Total

Reimbursement Per Enrollee (Price, Age, Sex and Race Adjusted)

\begin{tabular}{lcc}
\hline Reimbursement type & $R$ & $R^{2}$ \\
Total Medicare & -0.435 & 0.189 \\
Hospital and skilled nursing facility & -0.360 & 0.130 \\
Physician & -0.198 & 0.039 \\
Outpatient facility & +0.025 & 0.001 \\
Home health agency & -0.454 & 0.207 \\
Hospice & -0.276 & 0.076 \\
Durable medical equipment & -0.350 & 0.123 \\
\hline
\end{tabular}

likely that during this period, tort reform there may not have had a significant effect on medical expenditures because modern day health-care systems have gravitated toward cost-driven delivery models. ${ }^{19}$ In addition, data were not available to analyze Colorado and Louisiana, and only a single preceding year was available to be used as a baseline for Michigan.

Prereform and postreform data were obtained from the Dartmouth Institute and consisted of a 5\% sampling (Continuous Medicare History Sample obtained from CMS). These data were age, sex, and race adjusted. Data for the following reimbursements per enrollee were analyzed for years 1999-2007: total Medicare; total Medicare Part A; total Medicare Part B; professional and laboratory (Part B); medical costs (Part B); and diagnostic, laboratory, and X-ray (Part B). This analysis was carried out for Mississippi (PRI ranking 1), Nevada (PRI ranking 2), and Texas (PRI raking 6). The state data were also related to the national average reimbursements for each category.

To further investigate state findings, a second data set (claims data) was used, which consisted of a $20 \%$ sampling from 2003 to 2009 and a $100 \%$ sampling of 2010 and was adjusted for regional price variations, age, sex, and race. Using this data set, reimbursements for physician services were plotted for the 3 states and compared with the U.S. national average.

\section{Intrastate Variation}

To illustrate intrastate variations, a map of the Medicare Hospital Referral Regions is presented with a color scale representing varying degrees of traditional Medicare provider reimbursements per enrollee (Fig. 1). The map was constructed using 2010 claims data from the Dartmouth Institute that had 100\% sampling and was price, age, sex, and race adjusted. ${ }^{20}$ The sampling did not include Medicare Advantage plan enrollees.

\section{RESULTS}

\section{Medicare Reimbursements Compared With the Comprehensiveness of Medical Tort Reform}

The results of the national correlation between malpractice reform and Medicare utilization, based on aggregated state-level data, are shown in Table 1. Little, if any, correlation was observed in outpatient facility reimbursements. A negative correlation was observed in the other 6 comparisons (total Medicare, hospital and skilled nursing facility, physician, home health agency, hospice, and durable medical equipment), suggesting increased tort reform is linked to higher Medicare utilization. (In the PRI Scale, states ranked numerically between 1 and 50, with states with comprehensive tort reform at the bottom of the scale and states without significant tort reform at the top.) This finding is in the opposite direction to support the hypothesis that defensive medicine is a significant driver of health-care expenditures (Table 1).

\section{Prereform and Postreform Reimbursements}

To further elucidate the impact tort reform has had on healthcare utilizations, changes in state level reimbursement data over time was examined. Three states with comprehensive medical tort reform (Texas, Mississippi, and Nevada) were analyzed, and the Medicare reimbursements per enrollee overtime are shown in Figures $2 \mathrm{~A}$ and $\mathrm{B}, 3 \mathrm{~A}$ and $\mathrm{B}, 4 \mathrm{~A}$ and $\mathrm{B}$, and 5 . The number of enrollees who were sampled varied widely between the states. In the first data set (shown in Figs. 2A and B, 3A and B, and 4 A and $\mathrm{B})$, there was a $5 \%$ sampling, and the number of enrollees for Texas ranged from 73,746 to 90,566, for Mississippi from 14,949 to 15,912 , and for Nevada from 5,925 to 8,023. Similar findings were obtained for the second data set shown in Figure 5. Overall, $80 \%$ of the enrollees sampled resided in Texas. 


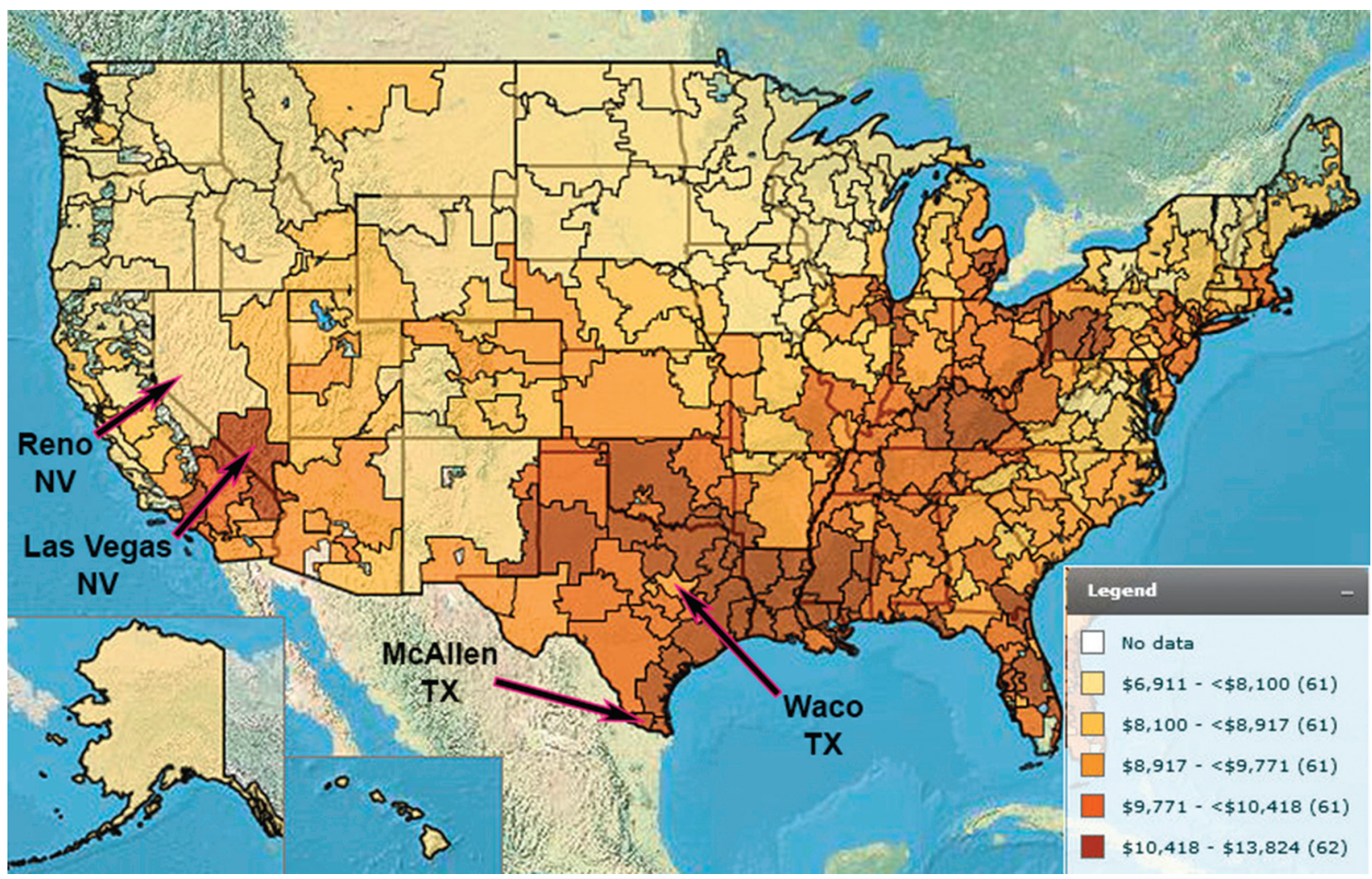

FIGURE 1. Traditional Medicare reimbursements per enrollee (dollars) by Medicare hospital referral region (price, age, sex and race adjusted), 2010 data - screen display from the Dartmouth Institute's Dartmouth Atlas of Health Care Website, accessed May 2, 2013, at www.dartmouthatlas.org. ${ }^{20}$

Mississippi had medical tort reform in 2002 and 2004. After 2004 , there is a tendency for an attenuation in the rate of increase of total Medicare Part B reimbursements, as compared with the U.S. average reimbursement (Fig. 2A). In addition, Figure 2B shows a tendency for lower utilization in Professional and Laboratory services and Medical Care after 2004, and Figure 5 shows a modest decrease in physician reimbursements after 2004. However, there is little observed effect on total Medicare reimbursements; total Medicare Part A reimbursements (Fig. 2A); and diagnostic, laboratory, and x-ray reimbursements (Fig. 2B).

Nevada had medical tort reform in 2002 and again in 2004. In 2004, comprehensive reform was enacted by eliminating exceptions to the $\$ 350,000$ noneconomic damages cap, eliminating joint liability, limiting attorney fees, and permitting periodic settlement payments. ${ }^{21}$ Little effect of tort reform can be seen in Figure $3 \mathrm{~A}$ or B on various reimbursement categories. There was a small $4.6 \%$ decrease in Part B medical care and professional and laboratory services the year after passage of more comprehensive reform in 2004. However, these effects seem to be transitory and were not evident in physician service reimbursements from the second data set, which had a larger sampling (Fig. 5).

Texas had $80 \%$ of the sampled Medicare enrollees and enacted tort reform in 2003. Figures $4 \mathrm{~A}$ and B and 5 shows an unexpected increase in all Medicare reimbursement categories after 2003, as compared with average U.S. Medicare expenditures.

\section{Intrastate Variations}

Figure 1 shows Medicare reimbursements per enrollee by Medicare Hospital Referral Region (price, age, sex, and race adjusted). Wide variations of Medicare reimbursement within states are evident. For example (using 2010 data), in Nevada (ranked second in comprehensive tort reform by PRI), the state is split, with the Reno, NV, region in the lowest reimbursement category (with an average of $\$ 7999$ per Medicare enrollee), whereas the Las Vegas region was in the highest category, with a 34\% higher average reimbursement of $\$ 10,734$ per Medicare enrollee (Fig. 1). Texas is ranked sixth by PRI in comprehensive tort reform but has one of the most expensive Medicare Hospital Referral Regions in the United States, McAllen, TX, with a Medicare reimbursement of $\$ 13,824$ per enrollee. This region is $48 \%$ more expensive than the Waco, TX, referral region, which receives a Medicare reimbursement of $\$ 9346$ per enrollee.

\section{DISCUSSION}

Our observations support the possibility of a slight trend of higher utilization of medical services in some states with comprehensive tort reform. This finding is inconsistent with the hypothesis that defensive medicine is a significant driver of medical overutilization or a meaningful contributor to the country's rising health-care costs.

Our analysis of the relationship between the state PRI medical tort reform index and Medicare reimbursements reveals a slight trend of higher utilization of medical services in states with more comprehensive reform (Table 1). Again, this contradicts the theory that tort reform decreases defensive medicine. The $R^{2}$ values of the negatively correlated reimbursements revealed that, depending upon the type of reimbursement, tort reform only accounted for $4 \%$ to $21 \%$ of the observed variance between the states.

This trend was also observed in Texas, comparing premedi$\mathrm{cal}$ and postmedical tort reform data (Fig. 4A and B). Piak et $\mathrm{al}^{22}$ 

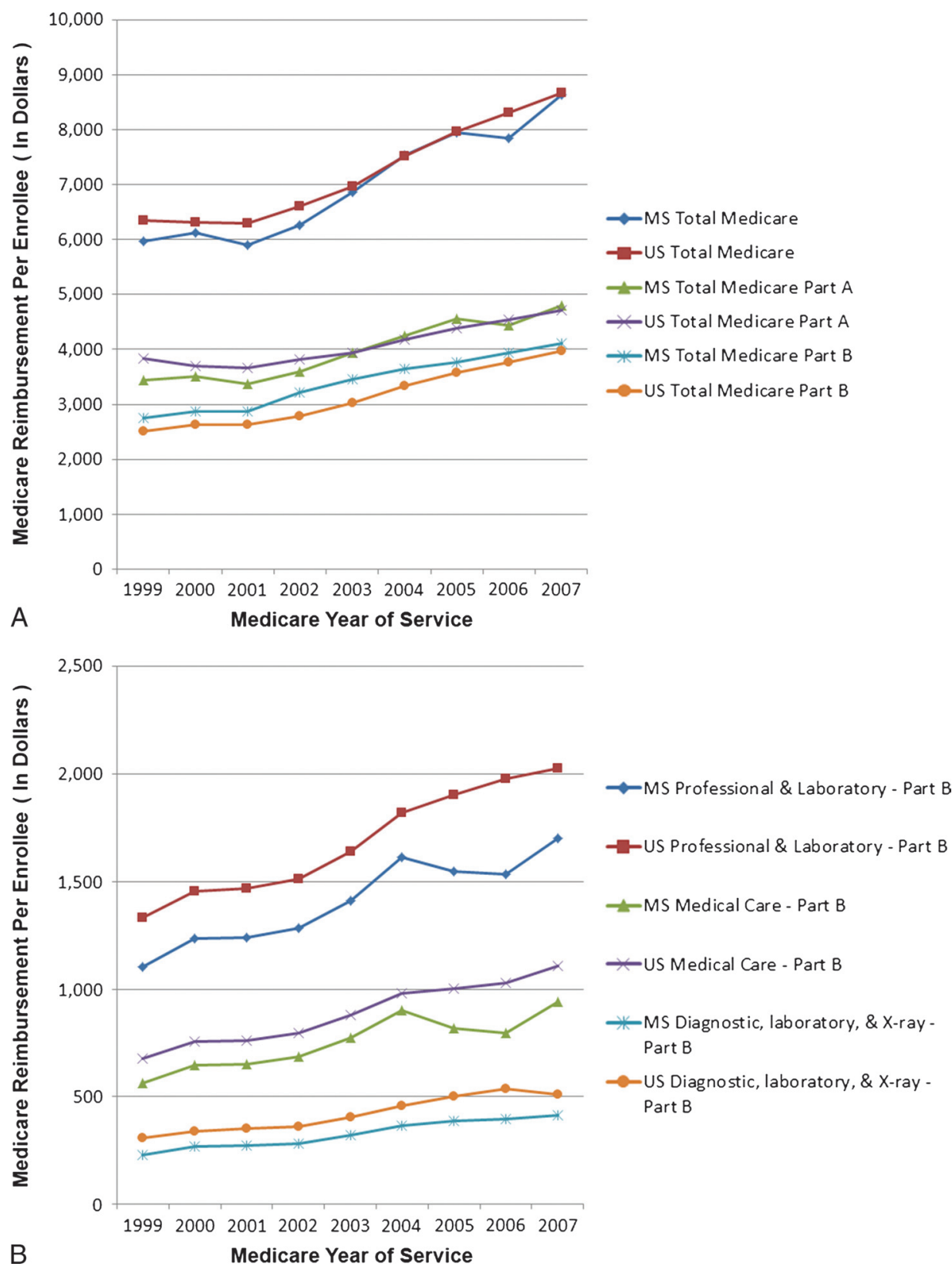

FIGURE 2. Traditional Medicare utilization per Enrollee (dollars) in the State of Mississippi (MS) for years of service of 1999-2007-Tort Reform in 2002 and 2004. Reimbursements are compared with US average reimbursement for each category. Data are age, sex, and race adjusted - from the Dartmouth Institute. A, Total Medicare, Medicare Part A and Medicare Part B reimbursements. B, Professional and Laboratory (Part B); Medical Costs (Part B); and Diagnostic Laboratory, and X-Ray (Part B) reimbursements.

also observed a similar trend in Texas. This is the opposite finding to that which was expected.

Of concern is that decreased accountability may result in an increase in overutilization in cost-driven systems. To quote Denham et al, many believe "Defensive medicine is as much a defense of volume as it is a defense of frivolous malpractice claims." ${ }^{23}$ Some may also feel that this analysis supports the contention that malpractice reform weakens accountability and, thus, allows costdriven systems to provide higher utilization of health care.

However, the number of observations contained in the data presented in Table 1 was small. There was little or no correlation observed with outpatient facility reimbursement, and the negative correlations were weak (Table 1). In addition, although a trend for increased reimbursements postenactment of reform was observed in Texas, it was not observed in Nevada, and in Mississippi, there was a possible modest decrease in reimbursements for physician and some outpatient (Part B) services.

It is also possible that differing methodologies of state medical tort rankings might yield a variation in results. In our analysis, we used the methodology of a conservative think tank, PRI, for data analysis because PRI's data regarding the cost of defensive medicine has been used by the Heartland Institute ${ }^{18}$ and the Massachusetts Medical Society ${ }^{14}$ and can be found on the state of Florida's Website. ${ }^{24}$ 

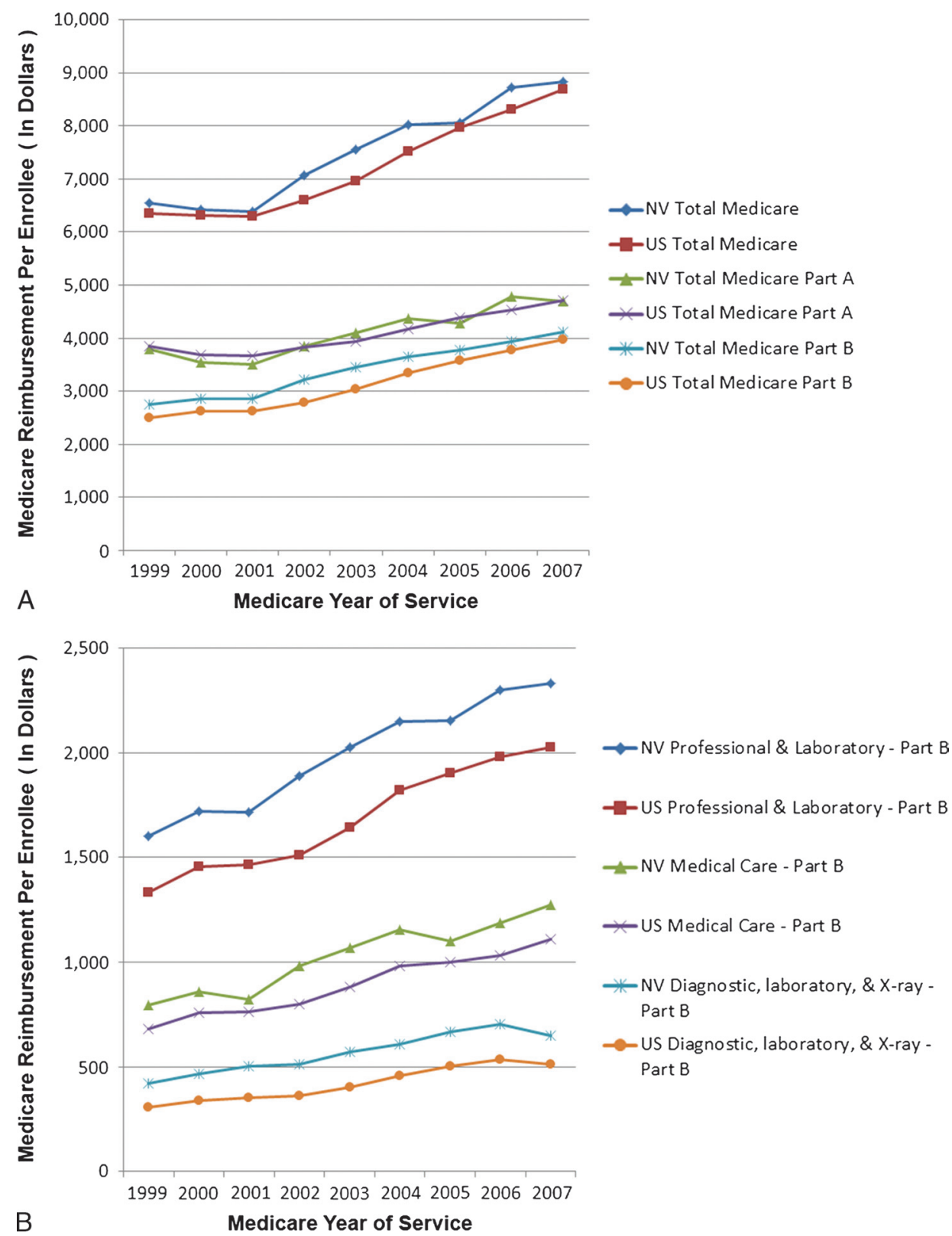

FIGURE 3. Traditional Medicare utilization per Enrollee (dollars) in the State of Nevada (NV) for years of service of 1999-2007-Tort Reform in 2002 and 2004. Reimbursements are compared with U.S. average reimbursement for each category. Data are age, sex and race adjusted - from the Dartmouth Institute. A, Total Medicare, Medicare Part A and Medicare Part B reimbursements. B, Professional and Laboratory (Part B); Medical Costs (Part B); and Diagnostic Laboratory, and X-Ray (Part B) reimbursements.

What can be more firmly stated is that there did not seem to be a significant total Medicare reimbursement savings with enactment of tort reform. This is in line with the findings of Thomas et al. ${ }^{25}$ In a review of 35 clinical specialties, the authors found the results of studies regarding the cost of defensive medicine were inconclusive and concluded that for every $10 \%$ reduction in premiums, there was only a $1 \%$ reduction in medical costs across specialties. ${ }^{25}$ Baicker et $\mathrm{al}^{26}$ also observed that an increase of $10 \%$ in malpractice payments per physician was associated with a $1 \%$ increase in Medicare payments for total physician services; similar observations were made for malpractice premiums. "Our findings add to the accumulating body of literature that defensive medicine may not be an important driver of healthcare costs."

\section{An Undetected Confounding Factor}

Two observations argue against other confounding factors negating the effect of tort reform enactment and accounting for higher utilization rates that are depicted in Table 1.

The first is that there can be substantial differences of utilization within a state (Fig. 1). Wide regional variations can be seen in Nevada and Texas, where utilization between the regions of Reno and Las Vegas varied by $34 \%$, and in where reimbursement between McAllen and Waco varied by $48 \%$ (see Fig. 1).

The large variation of reimbursements per enrollee within a state is a key observation that points to cost-driven health-care systems being at the heart of the problem. It is unlikely that the variations seen between McAllen and Waco in Texas or those 

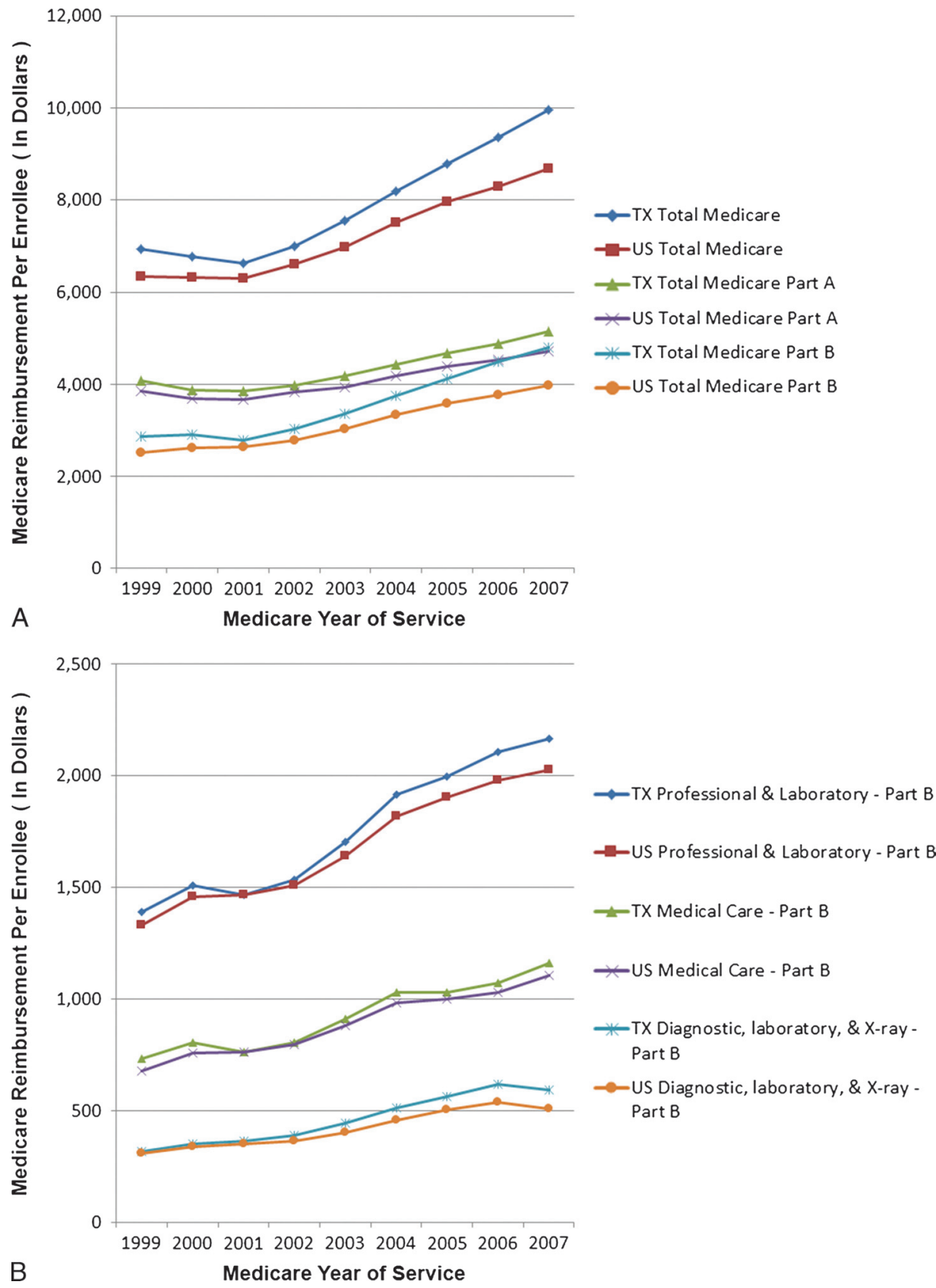

FIGURE 4. Traditional Medicare utilization per Enrollee (dollars) in the State of Texas (TX) for years of service of 1999-2007-Tort Reform in 2003. Reimbursements are compared with U.S. average reimbursement for each category. Data are age, sex and race adjusted-from the Dartmouth Institute. A, Total Medicare, Medicare Part A and Medicare Part B reimbursements. B, Professional and Laboratory (Part B); Medical Costs (Part B); and Diagnostic Laboratory, and X-Ray (Part B) reimbursements.

between Las Vegas and Reno in Nevada are due to differences in patient population. Both states have enacted comprehensive medical tort reform. Similar variations can be found in California, Arkansas, and New York. ${ }^{20}$

The second is that, when data are compared over time, there is not a consistent pattern to the effect on reimbursement after passage of tort reform. In Nevada, medical tort reform seemed to have had little effect on Medicare reimbursements (Figs. 3A and $\mathrm{B}$ and 5). In Mississippi (Figs. 2A and B and 5), after the 2004 tort reform, there was a tendency for decreased reimbursements in physician and some outpatient services. However, in Texas, there was a tendency for an increase in reimbursements faster than the U.S. average. In none of the 3 states was there an observable decrease in total Medicare reimbursements.

In Texas, tort reform was touted as a "vote for your doctors and for affordable health care." 27 However, other researchers have also not observed a savings in health-care costs after passage of reform. ${ }^{24,27}$ Piak et al examined the effects of tort 


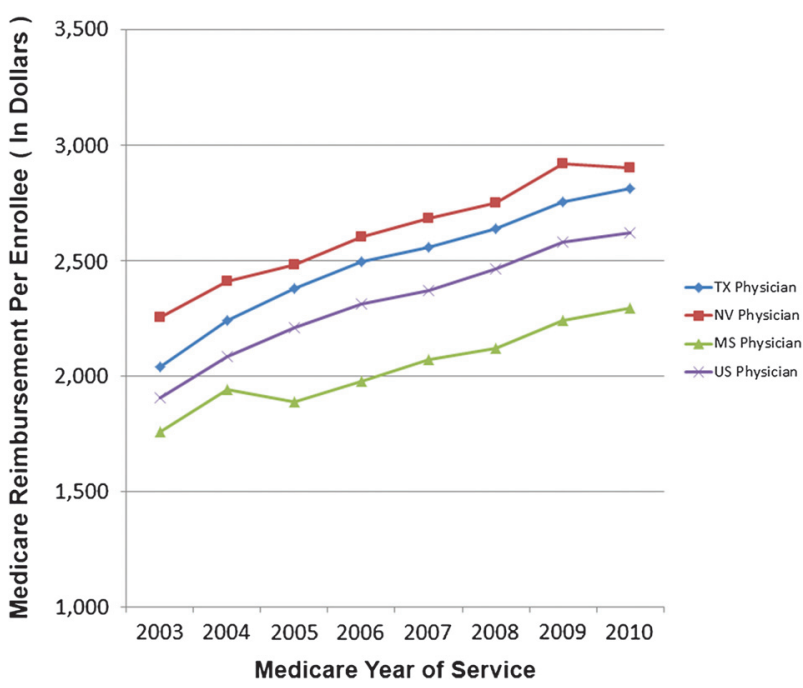

FIGURE 5. Traditional Medicare utilization per enrollee (dollars) for Physician Services in the States of Texas (TX), Nevada (NV), and Mississippi (MS) for years of services of 2003-2010. Reimbursements for Physician services are compared with U.S. average reimbursement. Data are price, age, sex, and race adjusted_from the Dartmouth Institute.

reform in Texas. ${ }^{22}$ They performed a county-level analysis and found no evidence that tort reform decreased health-care spending in "low-malpractice risk" counties and found "some evidence of increased physician spending in high-malpractice risk counties." They concluded that they could find no evidence that tort reform lowered health-care costs. Lincoln et al also observed that after tort reform was enacted in Texas, Medicare spending and private insurance premiums in Texas have risen faster than the national average. ${ }^{27}$

Taken as a whole, these 3 states gave inconsistent results and did not produce convincing evidence that enactment of medical tort reform saves a significant amount in total Medicare expenditures. The observed variations in results may be reflective of the philosophy of the medical community (cost driven versus patient centered).

\section{Current Tort Reform May Not Produce Enough Relief}

It is also possible that, despite the many provisions in tort reform and the lowering of the amount of noneconomic damages, there can still be a significant risk of financial loss. One can argue this point using the example in Nevada where in 2008, about 3000 medical liability suits were filed over the possible contraction of Hepatitis $\mathrm{C}$ at a gastroenterology clinic, regardless of the plaintiff's hepatitis $\mathrm{C}$ status ${ }^{21} ; 114$ cases were possibly linked to treatment at the clinic. ${ }^{28}$ A recent award of over $\$ 500,000,000$ dollars was given to 3 plaintiffs for punitive damages. ${ }^{29}$ Criminal charges have been also been filed, raising the question if tort reform has the potential of switching malpractice from the civil to the criminal arena. ${ }^{30}$ Depending upon the policy, malpractice insurance may pay for punitive damages, which are leveled for gross negligence. However, many carry an exclusion for criminal acts that violate a statue or law.

In contradistinction, in 2004, Mississippi tort reform created a more comprehensive limit on noneconomic damages, which was associated with a decreased number of Ob-Gyn lawsuits filed per year from an average of 44 to almost 15 , along with reducing malpractice premiums. ${ }^{31}$ In this example, it can be argued that the impact of reform had decreased Medicare reimbursements.
However, our analysis indicates that the economic impact was less profound, with a modest decrease in physician and some outpatient services but without an appreciable effect on total Medicare reimbursements.

Finally, physicians have malpractice insurance to shield them from financial loss. However, even a reduced chance of a significant financial penalty may still elicit defensive medicine. The process of going through a lawsuit is extremely stressful and emotionally draining for all parties involved, regardless of the financial loss or gain. A no-fault system such as that adopted by Sweden, Denmark, Finland, and New Zealand may address this concern. ${ }^{32}$ Vermont is also investigating this type of system. ${ }^{33}$ These systems would be expected to provide free health care to the patient to treat the event, to have no fault placed, and to have transparency of claims paid. However, there has not been a groundswell of support in the United States from either plaintiffs or defendants on adopting such a system.

\section{Remedies for Health-care Overutilization}

If tort reform is not a definitive answer to overutilization, what else can be done? A wide variety of possible mechanisms to reform health-care expenditures can be implemented with accountable care organizations (ACOs). These organizations are designed to share the risk between providers and insurers and are often mentioned as a mechanism for implementation of bundled payments. ${ }^{34}$ Participation in ACOs is voluntary. Initial evaluations of ACOs whose primary focus is the rewarding for quality have not reported significant health-care savings. ${ }^{35,36}$ However, the use of bundled payments produced a savings of $10 \%$ for coronary bypass surgeries. ${ }^{35}$ Almost 1 in 4 doctors are participating in or plan to participate in ACOs, and a significant number of private insurance companies are also participating. ${ }^{34}$ Accountable care organizations are similar to HMOs such as Kaiser Permanente, which is an integrated health-care delivery system. However, the governance structure of ACOs can be different, and CMS allows them to experiment with new types of payment systems.

One caveat with the ACO governance structure is that the fiduciary responsibility of ACO boards is to the ACO, and board members "must act consistent with that fiduciary responsibility." 37 ACO boards are designed to be composed primarily of providers, ${ }^{37}$ but providers are increasingly becoming employees of large integrated hospitals systems, ${ }^{38}$ which may also be cost driven. ${ }^{19}$

To control the ever increasing health-care expenditures, a bundled payment system may be necessary, but to assure healthcare quality, such a system must be patient centered, and safeguards must be in place to prevent medical underutilization by cost-driven systems.

\section{LIMITATIONS OF THE STUDY}

As with any study on this topic, statistical significance is hard to prove because the number of states in the analysis is limited to 50. It is also difficult to prove a negative. However, the effects of tort reform is a very important policy topic and decision making on tort reform policy by legislators, mimics courtroom litigation; a decision needs to be made, and it is based on the best available data. In addition, there is a difference between statistical significance and relevance. Even if the number of observations were increased, the change may be real but still not nearly large enough to have a meaningful effect on the Medicare budget. In addition, data from Medicare Advantage Plans were not available for analysis. Because Medicare Advantage Plans are predominantly managed care plans, many of which have precertification and utilization control, one would expect even less of an effect on these Medicare provider reimbursements with tort reform. 


\section{CONCLUSIONS}

The comparison of data from the Dartmouth Institute of Medicare reimbursement per enrollee with the PRI's malpractice reform state rankings did not support the hypothesis that defensive medicine is a significant driver of medical overutilization and rising health-care costs.

Medicare reimbursements per enrollee were tracked over time, prereform and postreform, for 3 states. In Texas, where $80 \%$ of the analyzed Medicare enrollees resided, a trend was observed of increasing Medicare reimbursements, as compared with the U.S. average, after tort reform in most analyzed categories. There was little discernible effect observed in Nevada and a trend for reduced reimbursements for physician services in Mississippi. In none of the 3 states did total Medicare expenditures seem to be substantially affected by tort reform.

The question arising from this study is as follows: Does a decrease in accountability increase or decrease healthcare utilization? The answer may vary in each community and depend on whether income and volume are the primary motivators in the provision of health care (cost-driven systems) or if goals are centered on the patient. As a mechanism for total Medicare cost savings, medical tort reform seemed to have little to no effect.

This is not to say that tort reform is not needed. Both plaintiffs and defendants vehemently complain about the system; some medical specialties are still severely impacted by costly premiums. However, our analyses indicate that defensive medicine may not be a major driver of increasing health-care costs. If tort reform is undertaken, it should be done in the context of not promoting overutilization in cost-driven systems.

\section{REFERENCES}

1. Health Expenditures. In: OECD Factbook 2013. Available at: http://www.oecd-ilibrary.org/economics/oecd-factbook_18147364. Accessed September 4, 2013.

2. Medicare Payment Policy. Report to Congress. March 2013. Available at: http://www.medpac.gov/documents/Mar12_EntireReport.pdf. Accessed September 4, 2013

3. Medicare Spending and Financing Fact Sheet, Overview of Medicare Spending. The Henry J. Kaiser Family Foundation. Nov 14, 2012. Available at: http://kff.org/medicare/fact-sheet/ medicare-spending-and-financing-fact-sheet/. Accessed July 31, 2013.

4. Chassin MR, Galvin RWJ. The urgent need to improve healthcare quality. JAMA. 1998;280:1000-1005.

5. Skinner J, Fisher E. Reflections on geographic variations in US. Health Care. The Dartmouth Institute. March 31, 2010 (updated May 12, 2010). Available at: http://www.dartmouthatlas.org/downloads/press/ Skinner_Fisher_DA_05_10.pdf. Accessed May 21, 2013.

6. Berrington de González A, Mahesh M, Kim KP, et al. Projected cancer risks from computed tomographic scans performed in the United States in 2007. Arch Intern Med. 2009;169:2071-2077. doi: 10.1001/archinternmed.2009.440.

7. Sodickson A, Baeyens PF, Andriole KP, et al. Recurrent CT, cumulative radiation exposure, and associated radiation-induced cancer risks from CT of adults. Radiology. 2009;251:175-184. doi: 10.1148/ radiol.2511081296

8. Smith-Bindman R, Miglioretti DL, Johnson E, et al. Use of diagnostic imaging studies and associated radiation exposure for patients enrolled in large integrated health care systems, 1996-2010. JAMA. 2012;307:2400-2409. doi: 10.1001/jama.2012.5960.

9. Prevedello LM, Raja AS, Zane RD, et al. Variation in use of head computed tomography by emergency physicians. Am J Med. 2012;125:356-364. doi: 10.1016/j.amjmed.2011.06.023. Epub 2012
Feb 10. Available at: http://www.amjmed.com/article/ S0002-9343(11)00570-5/abstract. Accessed May 10, 2013.

10. Chan PS, Patel MR, Klein LW, et al. Appropriateness of percutaneous coronary intervention. JAMA. 2011;306:53-61.

doi: 10.1001/jama.2011.916. Available at: http://jama.jamanetwork.com/article.aspx?articleid=1104058. Accessed May 10, 2013.

11. Al-Khatib SM, Hellkamp A, Curtis J, et al. Non-evidence-based ICD implantations in the United States. JAMA. 2011;305:43-49. doi: 10.1001/jama.2010.1915. Available at: http://jama.jamanetwork.com/article.aspx?articleid=644551. Accessed May 4, 2013.

12. Carroll J. Going on the offensive against defensive medicine. Managed Care Magazine. March 2005. Available at: http://www.managedcaremag.com/archives/0503/0503.regulation.html. Accessed May 4, 2013.

13. McQuillan, LJ, Abramyan H, Archie A. Jackpot justice: the true cost of America's tort system. Pacific Research Institute, 2007. Available at: http://heartland.org/policy-documents/jackpot-justice-true-costamericas-tort-system. Accessed May 4, 2013.

14. Massachusetts Medical Society. Investigation of defensive medicine in Massachusetts. Nov. 2008. Available at: http://www.ncrponline.org/ PDFs/2008/Mass_Med_Soc.pdf. Accessed May 4, 2013.

15. Hendee WR, Becker GJ, Borgstede JP, et al. Addressing overutilization in medical imaging. Radiology. 2010;257:240-245. doi: 10.1148/radiol.10100063. Epub 2010 Aug 24.

16. The Dartmouth Atlas of Healthcare. State Level Medicare Reimbursements 2010 Data file. Available at: http://www.dartmouthatlas.org/downloads/tables/ pa_reimb_state_2010.xls. Accessed May 2, 2013.

17. Graham JR. Medical tort: ranking the 50 states. Health Policy Prescriptions. Pacific Research Institute. 2010;8:1-3. Available at: http://heartland.org/sites/all/modules/custom/heartland_migration/files/ pdfs/28041.pdf. Accessed May 2, 2013.

18. The Heartland Institute. Available at: http://heartland.org/policydocuments/medical-tort-ranking-50-states. Accessed May 2, 2013.

19. Gawande A. The Cost Conundrum Redux. The New Yorker. June 23, 2009. Available at: http://www.newyorker.com/reporting/2009/06/01/ 090601fa_fact_gawande. Accessed May 10, 2013.

20. The Dartmouth Atlas of Healthcare. Medicare Reimbursements. Available at: http://www.dartmouthatlas.org/data/ map.aspx .ind $=225 \& \mathrm{ch}=191 \& \mathrm{tf}=23$ \&loct $=3$ \&extent $=-14071323$. $410590487 \% 202305693.8872850095 \% 20-7398676$. 589409513\%206806306.112714991. Accessed May 2, 2013.

21. Redfern F. Medical Liability reform comes full circle in Nevada. AAOS Now. Aug. 2008. Available at: http://www.aaos.org/news/aaosnow/ aug08/reimbursement4.asp. Accessed May 8, 2003.

22. Paik M, Black BS, Hyman DA, et al. Will tort reform bend the cost curve? Evidence from Texas. J Emp Legal Stud. 2012;9:173-216.

23. Denham CR, Swensen SJ, Henderson MJ, et al. The five rights of imaging: patient-centered performance. J Patient Saf. 2013;9. Prepublished ahead of print Apr. 30, 2013.

24. McQuillan LJ, Abramyan H. U.S. Tort Liability Index: 2010 Report. State of Florida Depart of Heath Website. Available at: http://www.doh.state.fl.us/Workforce/Workforce/Council_Materials/ Tort_Liability_Index_2010.pdf. Accessed on September 4, 2013.

25. Thomas JW, Ziller EC, Thayer DA. Low costs of defensive medicine, small savings from tort reform. Health Aff (Millwood). 2010;29:1578-1584. doi: 10.1377/hlthaff.2010.0146.

26. Baicker K, Fisher ES, Chandra A. Malpractice liability costs and the practice of medicine in the Medicare program. Health Aff (Millwood). 2007;26:841-852. PMID: 17485765. 
27. Lincoln T. A Failed Experiment: Health Care in Texas Has Worsened in Key Respects Since State Instituted Liability Caps in 2003. Washington, DC: Public Citizen's Congress Watch; October 2011. Available at http://www.citizen.org/documents/a-failed-experiment-report.pdf.

28. Manning M. Nevada hepatitis C outbreak largest in U.S. Las Vegas Sun. Available at: http://www.lasvegassun.com/news/2008/oct/23/ new-numbers-revealed-hepatitis-c-outbreak/. Accessed September 4, 2013.

29. Ritter K. Nev. Jury orders HMO to pay $\$ 500 \mathrm{M}$ in Hepatitis case. Yahoo News. Associated Press. April 9, 2013. Available at: http://news.yahoo.com/ nev-jury-orders-hmo-pay-500m-hepatitis-case-020558996-finance.html. Accessed May 14, 2013.

30. Lupian J. Jury seated for hepatitis C criminal trial. May 6, 2013. Available at: http://www.ktnv.com/news/local/206311721.html. Accessed May 15, 2013.

31. Karmasek JM. Attorney: Tort reform working in Mississippi. Legal Newline Legal Journal. July 15, 2011. Available at: http://legalnewsline.com/issues/ tort-reform/233383-attorney-tort-reform-working-in-mississippi. Accessed on May 19, 2013.

32. Dobbs D. Malpractice Mess Do the Swedes have a faultless fix Slate. Feb 22. 2005. Available at: http://www.slate.com/articles/ news_and_politics/how_they_do_it/2005/02/malpractice_mess.html. Accessed May 4, 2013.

33. Senate Proposal of Amendment. H. 202 An Act Relating to a universal and unified health system. State of Vermont. 2012. Available at:
http://www.leg.state.vt.us/docs/2012/bills/Senate/H-202.pdf. Accessed May 4, 2013.

34. Japsen B. Doctors Rush To Obamacare's Accountable Care Approach. Forbes. Available at: http://www.forbes.com/sites/brucejapsen/2013/04/ 27/doctors-rush-to-obamacares-accountable-care-approach/. Accessed April 27, 2013.

35. Nelson L. Lessons from Medicare's Demonstration Projects on Disease Management, Care Coordination, and Value-Based Payment. Congressional Budget Office. Issue Brief. Available at: http://www.cbo.gov/ftpdocs/126xx/doc12663/01-18-12-Medicare DemoBrief.pdf. Accessed September 4, 2013.

36. Eddy DM, Shah R. A simulation shows limited savings from meeting quality targets under the Medicare Shared Savings Program. Health Aff (Millwood). 2012;31:2554-2562. doi: 10.1377/hlthaff.2012.0385. Epub 2012 Oct 3.

37. Medicare Program, Medicare Shared Savings Program: Accountable Care Organizations. Centers for Medicare and Medicaid Services. Federal Register. (42 CFR Part 425) 2011;78(212):67819. Available at: at http://www.gpo.gov/fdsys/pkg/FR-2011-11-02/pdf/2011-27461.pdf. Accessed May 4, 2013.

38. Kocher R, Sahni NR Hospitals' race to employ physicians-the logic behind a money-losing proposition. $N$ Engl J Med. 2011;364: 1790-1793. Available at: http://www.nejm.org/doi/full/10.1056/ NEJMp1101959. Accessed May 4, 2013. 